\title{
A Bidirectional Associations between Urban Physical Environment and Mental Health: A theoretical framework
}

\author{
Marlyana Azyyati Marzukhi1, Nur Masyitah Ghazali2, Oliver Ling Hoon Leh¹, Hamizah Yakob¹ \\ ${ }^{1}$ Centre of Studies for Town and Regional Planning, Faculty of Architecture, Planning \& Surveying, \\ Universiti Teknologi MARA, Puncak Alam, Malaysia. \\ ${ }^{2}$ Centre of Graduate Studies, Faculty of Architecture, Planning \& Surveying, \\ Universiti Teknologi MARA, Shah Alam, Malaysia.
}

marlyana@uitm.edu.my, masyitah.ghazali@gmail.com, oliver3979@uitm.edu.my, hamizah1204@gmail.com $+60133953379$

\begin{abstract}
This paper examines the influence of the urban physical environment on mental health. A scoping review of reviews and a search of keywords from 109 international literatures from 1985 to 2019 conducted in a relevant database such as SCOPUS, Web of Science, and PubMed and snowballing method in the references list to get a recent paper that related. The relationship developed in the form of a theoretical framework using urban health indicators that identifies a relationship between the urban physical environment and mental health. The framework can be beneficial to the urban planning decision-makers to plan healthier and more sustainable Malaysian cities.
\end{abstract}

Keywords: Urban Physical; Environment; Mental; Health

eISSN: 2398-4287 @ 2020. The Authors. Published for AMER ABRA cE-Bs by e-International Publishing House, Ltd., UK. This is an open access article under the CC BYNC-ND license (http://creativecommons. org/licenses/by-nc-nd/4.0). Peer-review under responsibility of AMER (Association of Malaysian Environment-Behaviour Researchers), ABRA (Association of Behavioural Researchers on Asians) and cE-Bs (Centre for Environment-Behaviour Studies), Faculty of Architecture, Planning \& Surveying, Universiti Teknologi MARA, Malaysia.

DOI: https://doi.org/10.21834/e-bpj.v5i13.2048

\subsection{Introduction}

World Health Organization (WHO) in the World Health Report (2019) stated that around 450 million people had a mental disorder and causing it to become the leading for health problems and disability worldwide. Most of suicide and self-harm cases reported was due to mental disorder, as United Nations (UN) reported approximately one million commit suicide every year and it also ranked as the third leading cause of death among young people. Apart from that, currently, more than 4 billion people living in urban areas and UN-Habitat predicted about 60 per cent of the world's population which is more than 5 billion people would live in urban areas by the year 2030. This figure will keep increasing by the year. As the world's population will move into the urban area, the built environment could play an essential role in the improvement of mental health (Ceñido et al., 2019). In Malaysia, the urbanisation trends are also increasing by the year. According to the United Nations (2018) in World Urbanisation Prospect 2018 for the year of 2017, 75 per cent of the population is living in urban areas. Lau (2016) claimed that mental health problems expected to be the second biggest health problem in Malaysia. As such, it is crucial to understand the impact of the urban physical environment on mental health. This paper will study the bidirectional relationship between urban physical environments and mental health. A bidirectional defined as operating or functioning in two directions. In contrast, associations in psychology represent some types of connection between ideas, behaviours, events, objects, or feelings that are conscious or unconscious. While the definition of the bidirectional relationship between the urban physical environment and mental health is a two-way relationship that both the urban physical environment and mental health affecting each other.

eISSN: 2398-4287 @ 2020. The Authors. Published for AMER ABRA cE-Bs by e-International Publishing House, Ltd., UK. This is an open access article under the CC BYNC-ND license (http://creativecommons.org/licenses/by-nc-nd/4.0/. Peer-review under responsibility of AMER (Association of Malaysian Environment-Behaviour Researchers), ABRA (Association of Behavioural Researchers on Asians) and cE-Bs (Centre for Environment-Behaviour Studies), Faculty of Architecture, Planning \& Surveying, Universiti Teknologi MARA, Malaysia.

DOI: https://doi.org/10.21834/e-bpj.v5i13.2048 
According to Evans (2003), built environments can affect mental health in two significant ways, which are the characteristics of environmental characteristics, including housing, crowding, noise, indoor air quality, and light. This characteristic also indicates poor urban planning. Poor urban planning will cause many issues in the physical, environmental, and urban areas. It can create an overpopulated area, and thus the demand for housing will increase, and a higher density housing scheme built. It can cause low quality of housing and inadequate provision of facilities, including green areas. Poor urban planning also can result in massive traffic congestion, which can affect mental health as people need to be in traffic congestion for long hours daily and inadequate public transportation services to support urban population and increase of vehicles. Poor urban planning also may cause to lack of shared public spaces. Lack of public spaces provision may make a city dull due to no social interaction. Green spaces, plaza, or squares will make a city alive and gives more social interaction directly and indirectly. Thus a literature review is conducted, and a theoretical framework developed to have a better understanding of these bidirectional associations. This framework will illustrate the components of the urban physical environment and how it will affect mental health and what are the effects of it with details explanations of each element.

\subsection{Urban Physical Environment and Mental Health}

Studies have shown that urban physical environment can affect mental health directly and indirectly through its characteristics. World Health Organisation (WHO) defines health, in general, is not only regarding the absence of disease or infirmity but as a state of complete physical, mental, and social wellbeing. For mental health definition, it is a state of wellbeing in which every individual realises their potential, able to cope with the normal stresses of life, can work productively, fruitfully, and can make a contribution to the community (World Health Organisation, 2014). However, Galderisi et al. (2015) suggested the definition of mental health as "a dynamic state of internal equilibrium which enables individuals to use their abilities in harmony with universal values of society. Basic cognitive and social skills; ability to recognise, express and modulate one's own emotions, as well as empathise with others; flexibility and ability to cope with adverse life events and function in social roles; and harmonious relationship between body and mind represent important components of mental health contributing, to varying degrees, to the state of internal equilibrium". Meanwhile, Manwell et al. (2015) stated that mental health is a standard level of cognitive-emotional functioning and adaptation and a sense of coherence experience of understanding and managing stressors.

Halpern (2014) emphasises on the direct source of stressor through the built environment and indirectly through generating social support. Barton et al. (2009) define the sphere of direct planning influence towards human settlements is by the built environment, which is the physical form and management of places such as the buildings, spaces, streets, and networks. The urban physical environment is physical factors that comprise settlement area, facilities, utilities, green area, and transportation in the urban area (Guite et al., 2006, Handy et al., 2002 and Chu et al., 2004). Kim and Yoo (2019) found that land use, street environment, transportation infrastructure, green and open spaces, and neighbourhood facilities contribute to mental health problems. Furthermore, Guite et al. (2006) outlined five factors that act independently to predict poor mental health and vitality, which is noise annoyance, perceptions of crime, house overcrowding, access to green spaces, and community facilities. In this sense, Gruebner et al. (2012) and Gong et al. (2016) suggested the variable of the physical environment associated with mental health which natural environment, green spaces, land use, industrial activity, housing quality, access to basic services, traffic volume, sanitation, housing sufficiency, housing durability, and population density. A higher level of urbanisation increases the risk of a higher number of immigrants, a higher level of air pollution, lack of green provision and lack of social safety as both physical and social environment is found that have significant impacts towards mental health wellbeing (Generaal et al., 2019; Qiu et al., 2019).

\subsection{Methodology}

This research conducted using a scoping study that consists of five stages methodological framework for data extraction in the literature search (Arksey and O'Malley, 2005 and Hassen, 2016). Scoping studies are a form of knowledge synthesis addressing exploratory research questions aimed at mapping key concepts, types of evidence, and gaps in research. The first stage in the scoping study is to identify the research question, which is 'how does an urban physical environment affect mental health and wellbeing?'. The second stage is to identify the relevant studies and comprehensive searches via different sources that are using electronic databases such as SCOPUS, Web of Science, and PubMed. Then a snowballing is done through the reference lists and hand-searching of key journals using the keywords' urban physical environment AND urban environment AND mental health AND wellbeing'. After a database searching is complete, the next stage is study selection, which from a total of 109 references, 47 taken out as not captures the scopes of the research question. In a total of 62 references are charted by the aims of the study, and essential results extracted. The final stage is collating, summarise, and reporting the results by review the literature, evidence, and findings that answer the research question. Based on the literature review, a theoretical framework developed to summarise the relationship or urban physical environment towards mental health and supporting evidence to each of the components.

\subsection{Framework of Urban Physical Environment and Mental Health}

Urban environment definition, according to Ompad et al. (2007), is a specific characteristic of features of cities that influence health in three distinct concepts, which are social environment, the physical environment, and urban resource infrastructure. In this framework, the urban environment is consisting of three main characteristics in an urban physical environment, which built environment, natural 
environment, and activities. These three characteristics interlinked with each other, which makes it becomes a complete affinity for health determinants, which, as shown in Figure 1.

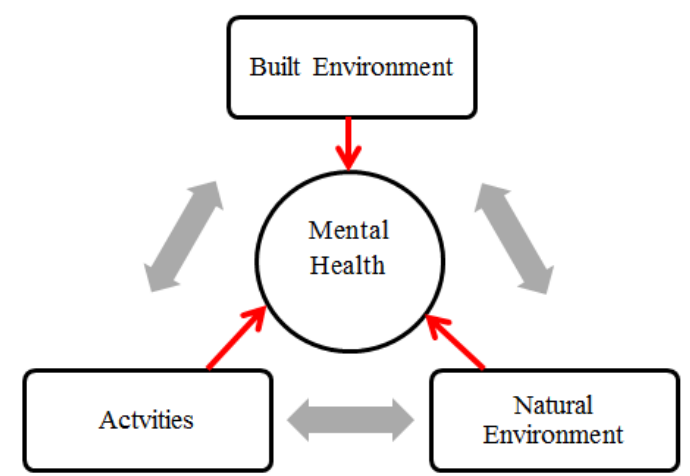

Fig 1: A Cycle of Relationship in Urban Physical Environment

The theoretical framework (refer Figure 2), each component will explain the relationship between urban physical health for a better understanding of how it can influence mental health. This framework, shown in Figure 2, illustrates the relationship of the urban physical environment with mental health wellbeing. This framework explains the character of the urban physical environment that gives effect directly or indirectly and how it is measured. Scopes divided into three main components, which the built environment, natural environment, and activities. The character underlying in each component has its significance on the effect of health in general and mental health problems. A built environment component is usually manmade consist of housing, crowding, park, transportation, services, utilities, and urban design.

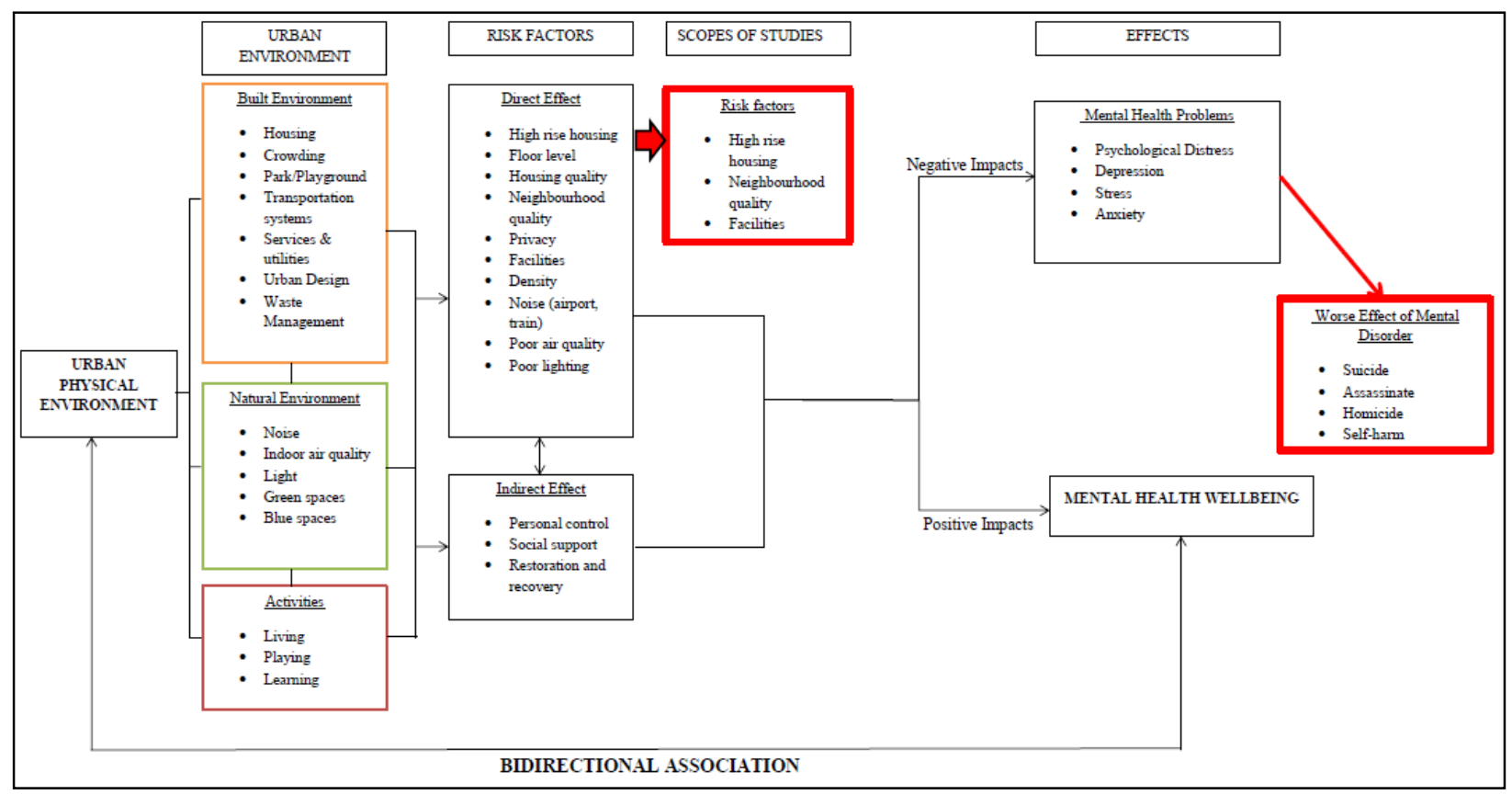

Fig 2: Framework of Bidirectional Association between Urban Physical Environment and Mental Health

\subsection{Urban Environment}

As shown in Figure 1 and Figure 2 above, the built environment in the urban physical environment can affect mental health directly and indirectly. The built environment is usually is manmade, and made for humans and human use such as housing, park, transportation, utilities, services, and urban design. The built environment and natural environment are related to each other as the built environment will provide access to the natural environment, and the built environment also can cause pollution and affect the natural environment. Both of built and natural environments are supported by activities component, which is people's activities in the built and natural environment. Activities consist of living, playing, and learning where each of these is related directly to the built environment and natural environment. Wang et al. (2019) stated that the quality of natural, built and social environments are associated with mental health. In previous research by Sarkar et al. (2018), it found that built environment density and the form of urban spaces in a city might affect mental health. According to Melis et al. (2015), urban density and accessibility of public transport can affect depressive symptoms among adults and decrease by the improvements of some features of the urban built environment. It is supported by Ceñido et al. (2019) which found improvement of walkability has positive changes for human behaviours and health outcomes. The built environment is not a 
stand-alone characteristic which closely related to natural environments such as green spaces, forests, trees, blue spaces, and also activities in which the events happens in both built environments and natural environments. The built environment can become one of the risks for depression for those who live in areas characterised as a poor quality, which linked to housing location and quality of the neighbourhood (Galea et al., 2005 and Friesinger et al., 2019). Hoisington et al. (2019) suggest that improving the condition of the built environment can improve mental health outcomes.

The natural environment is usually related to greenness, which can be open spaces, recreational areas, trees, landscapes, and other natural and other natural features. In a dwelling area, green spaces in very important for the residents to do both active and passive activities. It is also a meeting point of a community. A liveable residential environment represented different elements of physical urban form and role in achieving the quality of living and protecting the natural environment (Skalicky and Cerpes, 2019). Mitchell (2013) stated that the natural environment used for physical activities could lower the risk of mental health (Thompson et al., 2019) as it mitigates the effects of stress and stress-inducing factors. Zijlema et al. (2018) and Wendelboe-Nelson et al. (2019) found that commuting in natural environments can affect to better mental health due to exposure to the natural environment that can decrease negative affect. Natural environment or green spaces is linked to a higher level of sense of community and associated with improvements in mental health (Rugel et al., 2019). Liao et al. (2019) and Bezold et al. (2018) stated that residential that surrounded with green spaces, especially for people, live in higher density associated with better mental health, and it can reduce the level of traffic-related air pollution. Sefcik et al. (2019) and Wang et al. (2019) found strong evidence on improving and enhancing the quality and quantity of green spaces can improve mental health as more greenery correlates with positive mental health. The provision of green spaces and access to the natural environment will promote physical activities, which is vital to reduce poor mental health.

Activity is supported components for both built and natural environments. It is any activities that occur or take part in the built and natural environment such as living, playing, and learning. Liu et al. (2019) stated that physical activities, stress reduction, and neighbourhood social cohesion are complete mediation effects for the exposure that has to affect residents' mental health. Akpinar (2016) found that a higher frequency of physical activity and a larger size of greenspaces related to better mental health, and it also supported by research done by Liu et al. (2017) and Harvey et al. (2010), which suggests physical activities and nature interaction in parks improves mental health. Neighbourhood walkability and cognitive function is a physical activity which suggests higher walkable neighbourhood provides opportunities to do exercise, which has positives effect on mental health (Guo et al., 2019). As people living in a residential, it is essential to provide a place for physical activities to be done. All these three main components in the urban physical environment are related to each other; thus, it will give direct and indirect effects on mental health for its insufficiency.

\subsection{Risk Factors of Urban Physical Environment towards mental health}

As discussed earlier, the built environment, natural environment, and activities can give direct and indirect effects on mental health when the cycle is not complete or lacking provision. The characteristic of direct and indirect effects suggested by Evans (2003) is derived from the environment itself and affect mental health. Characteristics of the built environment, such as high-rise buildings, high density of urban areas or neighbourhood, lack of green spaces, and poor air quality, can give direct effects to the residents. There are many shreds of evidence from the previous research regarding the effect of the built environment that can directly affect mental health. Qiu et al. (2019) claimed that neighbourhood floor area ratio, building density, and green area correlated with mental health. James et al. (2016) and Miles et al. (2011) stated that people who live in higher density could increase physical and social problems, which resulted in poor mental health. It is not a new scenario, as Rohe (1985), in his research, found that residential with high density, traffic volume, and highrise housing associated with mental health. Housing with poor quality, lack of green areas, and noise and air pollution are related to poor mental health (Rautio et al., 2017). High-density population causes overcrowding in the area, which has a direct effect on mental health (Chu et al., 2004). James et al. (2016) stated that dense and walkable areas such as abandoned buildings, traffic noise, graffiti, litter, and crime could create psychosocial stressors.

As urban physical environment can directly affect mental health, it also can indirectly affect several characteristics of environments. Evans (2003), in his study, suggests personal control, social support, and restoration from fatigue and stress can be influenced by noise, crowding spatial hierarchy, distance, natural housing elements, and architecture. Latkin and Curry (2003) highlighted the association between neighbourhood characteristics and depressive symptoms, where social disorganisation become chronic stressors to the urban population. Wang et al. (2019) found that streetscapes greenery becomes buffer against stress and mitigates environment pollutions correlates with positive mental wellbeing. Guite et al. (2006) suggest that place to stop and chat, such as green spaces, plaza, nodes, and the intersection is essential for people's mental health especially whom experience damp, noise, overcrowding and fear of crime in their home and residential. Tsai et al. (2018) suggest the distance of residential with forest patches associated with a lower prevalence of frequent mental distress. Meanwhile, Ma et al. (2018) found that people living in a neighbourhood close to the main road have a higher prevalence of various mental health problems such as anxiety, fatigue, and sleep disturbance. It supported by Pun et al. (2019) in their studies that show road distance associated with depressive and anxiety symptoms because it reduces the level of loneliness and higher air pollution, which linked with urbanicity.

\subsection{Effects}

Several urban physical environment characteristics can, directly and indirectly, affect peoples' mental health, and due to these factors, the prevalence of mental health problems is increasing. It is at an alarming rate as not only can it cause mental health problems to a person, but it also may affect their surrounding people. Mental health problems attributed to a significant number of deaths around the world by suicide and self-harm. Mental health problem not only causing mortality but also, they have to lives in disability for years. Ferrari et al. (2014) stated that mental disorders associated with an increased risk of suicide. According to the World Health Organization (WHO) 
reported that ten people per 100,000 died from suicide in 2017 globally, and almost 800,000 persons die from suicide. An acute effect of air pollution in the urban area has a higher risk of suicide (Min. et al., 2018). Srivasta (2009) stated that mental health is affecting from urbanisation by the increased stressors and factors such as overcrowded, polluted environment, high level of violence, and reduced social support. The population density is causing physical and social problems, and it pressures on mental health (Berry, 2007). Barros et al. (2019) found that people were living in high-rise buildings associated with worse social effects and mental health outcomes due to the poor quality of their semi-public spaces. Xie et al. (2018) found that physical environments such as distribution, proximity, size, and quality of parks and road networks affect with low accessibility of parks will expose to higher health risks. Yang and Matthews (2010) stated that the imbalance between environment demand and individual coping may lead to a high level of stress and can cause mental disorders. Mental health problems will cause social exclusion as people with mental health will avoid social interaction, which means they will not go to the parks for activities and affecting the quality of life. In a deprived area, the facilities for the community usually inadequate, causing the residents to tend to stay at home and the community social cohesion lacking. Heekin and Polivka (2015) explain the effect of mental health problems have negative impacts on quality of life and physical health, social relationship strains, reduces labour supply, homelessness, self-harm, and suicide, and also a significant financial burden. There have been many cases involves people with mental health problems endangered and caught in murdering across the world. As mental health problems will be the second-highest non-communicable disease around the globe, but it also can affect physical health, suicidal, self-harm, and endanger other people's lives.

\subsection{Conclusions}

The urban physical environment can affect mental health; however, the strength of evidence on how urban physical environment affecting mental health is still lacking (Clark et al., 2007). From the previous literature, there is not much literature on mental health effects on the urban physical environment. Hence, a theoretical framework illustrated to develop an understanding of the bidirectional relationship between the urban physical environment and mental health. This framework highlights the characteristics of the urban environment and how this environment can affect directly and indirectly to mental health and what are the effects of the urban physical environment. This framework could be applied to support the implementation of the New Urban Agenda and in line with Sustainable Development Goals (SDG) to create a healthier urban environment in Malaysia.

\section{Acknowledgements}

The authors would like to express our gratitude to the Faculty of Architecture, Planning and Surveying, Universiti Teknologi MARA (UiTM); and Ministry of Higher Education Malaysia through Fundamental Research Grant Scheme (600-IRMI/FRGS 5/3 (063/2019) for their generous contribution towards this research.

\section{References}

Akpinar, A. (2016). How is quality of urban green spaces associated with physical activityand health? . Urban Forestry \& Urban Greening 16, 76-83.

Alize J. Ferrari, R. E. (2014). The Burden Attributable to Mental and Substance Use Disorders as Risk Factors for Suicide: Findings from the Global Burden of Disease Study 2010. PLOS ONE 9(4), 1-11.

Andrew J. Hoisinton, K. A.-Y. (2019). Ten questions concerning the built environment and mental health. Building and Environment 155, 59-69.

Annette Chu, A. T. (2004). The impact on mental wellbeing of the urban and physical environment: an assessment of the evidence. Journal Of Mental Health Promotion , 17-32.

Berry, H. L. (2007). 'Crowded suburbs' and 'killer cities': a brief review of the relationship between urban environments and mental health. NSW Public Health Bulletin 18 $(11-12), 222-227$.

Bo Xie, Z. A. (2018). Healthy aging with parks: association between park accessibility and the health status of older adults in urban China. Sustainable Cities and Society, $1-51$.

Carla P. Bezold, R. F. (2018). The relationship between surrounding greenness in childhood and adolescence and depressive symptoms in adolescence and early adulthood. Annals of Epidemiology, 1-25.

CatharineWard Thompson, A. E. (2019). Enhancing Health Through Access to Nature: How Effective are Interventions in Woodlands in Deprived Urban Communities? A Quasi-experimental Study in Scotland, UK. Sustainability 2019:11, 1-21.

Charlotte Clark, R. M. (2007). A systematic review of the evidence on the effect of the built and physical environment on mental health. Journal of Public Mental Health, Vol 6 Iss 2, 14-27.

CharlotteWendelboe-Nelson, S. K. (2019). A Scoping Review Mapping Research on Green Space and Associated Mental Health Benefits. International Journal of Environmental Research and Public Health, 1-49.

Chinmoy Sarkar, C. W. (2018). Residential greenness and prevalence of major depressive disorders: a cross-sectional, observational, associational study of 94879 adult UK Biobank participants. Lancet Planet Health 2018:2, e162-73. 
Curry, C. A. (2003). Stressful Neighborhoods and Depression: A Prospective Study of the Impact of Neighborhood Disorder. Journal of Health and Social Behavior, Vol. 44, No. 1, 34-44.

Danielle C. Ompad, S. G. (2007). Urbanicity, Urbanization,and the Urban Environment. In S. Galea, Macrosocial Determinants of Population Health (pp. 53-69). New York, United States: Springer ScienceBusiness Media, LLC.

Ellen Generaal, E. O. (2019). Neighbourhood characteristics and prevalence and severity of depression: pooled analysis of eight Dutch cohort studies. The British Journal of Psychiatry, 468-475.

Emily J. Rugel, R. M. (2019). Exposure to natural space, sense of community belonging, and adverse mental health outcomes across an urban region. Environmental Research 171, 365-377.

Evans, G. W. (2003). The Built Environment and Mental Health. Journal of Urban Health: Bulletin of the New York Academy of Medicine, Vol 80, No. 4, 536-537.

Giulia Melis, E. G. (2015). The Effects of the Urban Built Environment on Mental Health: A Cohort Study in a Large Northern Italian City. International Journal of Environmental Research and Public Health, 14898-14915.

H.F. Guite, C. C. (2006). The impact of the physical and urban environment on mental wellbeing. Journal of the Royal Institute of Public Health, 1117-1126.

Halpern, D. (2014). Mental health and the built environment: more than bricks and mortar? Routledge.

Hassen, N. (2016). The Influence of Green Space on Mental Health \& Well-being: A Scoping Review of Reviews. Toronto: Wellesley Institute.

Hilary Arksey, L. O. (2005). Scoping Studies: Towards a Methodological Framework. Int. J. Social Research Methodology 8(1), $19-32$.

Hongxiao Liu, F. L. (2017). The relationships between urban parks, residents' physical activity, and mental health benefits: A case study from Beijing, China. Journal of Environmental Management 190, 223-230.

Hugh Barton, M. G. (2009). Healthy urban planning in European cities. Health Promotion International, 91-99.

Jan Georg Friesinger, A. T. (2019). Studies regarding supported housing and the built environment for people with mental health problems: A mixed-methods literature review. Health and Place $57,44-53$.

Jiaqiang Liao, B. Z. (2019). Residential exposure to green space and early childhood neurodevelopment. Environment International 128, 70-76.

Jing Ma, C. L.-P. (2018). A Multilevel Analysis of Perceived Noise Pollution, Geographic Contexts and Mental Health in Beijing. International Journal of Environmental Research and Public Health, 1-18.

Jin-young Min, H.-J. K.-b. (2018). Long-term exposure to air pollution and the risk of suicide death: A population-based cohort study. Science of the Total Environment 628-629, 573-579.

Joshua F. Ceñido, C. F.-H. (2019). Environmental Interventions for Physical and Mental Health: Challenges and Opportunities for Greater Los Angeles. International Journal of Environmental Research and Public Health, 1-14.

Justine S. Sefcik, M. C. (2019). Perceptions of Nature and Access to Green Space in Four Urban Neighborhoods. International Journal of Environmental Research and Public Health, 1-13.

Kacey Heekin, L. P. (2015). Environmental and Economic Factors Associated with Mental IIIness. Florida: Florida State University.

Lau, B. (2016, October 10). One in three Malaysians have mental health problems as government action plan to be unveiled. Retrieved from MIMS Today: https://today.mims.com/one-in-three-malaysians-have-mental-health-problems-as-government-action-plan-to-be-unveiled

Laurie A Manwell, S. P. (2015). What is mental health? Evidence towards a newdefinition from a mixed methods multidisciplinary international survey. BMJ Open, 1-12.

Mitchell, R. (2012). Is physical activity in natural environments better for mental health than physical activity in other environments? Social Science \& Medicine, 1-5.

Nina Rautio, S. F. (2017). Living environment and its relationship to depressive mood: A systematic review. International Journal of Social Psychiatry, 1-12.

Oliver Gruebner, M. M. (2012). Mental health in the slums of Dhaka - a geoepidemiological study. BMC Public Health, 1-14.

Paula Barros, L. N. (2019). Social consequences and mental health outcomes of living in high-rise residential buildings and the influence of planning, urban design and architectural decisions: A systematic review. Cities $93,263-272$.

Peter James, J. E. (2016). Built Environment and Depression in Low-Income African Americans and Whites. American Journal of Preventive Medicine, 1-11.

Rebecca Miles, C. C. (2011). Neighborhood Urban Form, Social Environment, and Depression. Journal of Urban Health: Bulletin of the New York Academy of Medicine, Vol. 89, No. 1, 1-18.

Rohe, W. M. (1985). Urban planning and mental health. Prevention in Human Services, 79-110.

Ruoyu Wang, M. H. (2019). Urban greenery and mental wellbeing in adults: Cross-sectional mediation analyses on multiple pathways across different greenery measures. Environmental Research, 1-8.

Ruoyu Wang, Y. L. (2019). Depressive symptoms among Chinese residents: how are the natural, built, and social environments correlated? BMC Public Health, 1-8. 
Samuel B. Harvey, M. H. (2010). Physical activity and common mental disorders. The British Journal of Psychiatry , 357-364.

Sandro Galea, J. A. (2005). Urban built environment and depression: a multilevel analysis. Journal of Epidemiol Community Health, $822-827$.

Silvana Galderisi, A. H. (2015). Toward a new definition of mental health. World Psychiatry 14:2, 231-233.

Srivastava, K. (2009). Urbanisation and Mental Health. Industrial Psychiatry Journal, 75-76.

Susan L Handy, M. G. (2002). How the built environment affects physical activity: Views from urban planning. American Journal of Preventive Medicine 23(1), 64-73.

United Nations. (2018). World Urbanization Prospects 2018. Retrieved from United Nations: https://population.un.org/wup/DataQuery/

Vanja Skalicky, I. Č. (2019). Comprehensive assessment methodology for liveable residential environment. Cities 94, 44-54.

Vivian C. Pun, J. M. (2019). Close proximity to roadway and urbanicity associated with mental ill-health in older adults. Science of the Total Environment $658,854-860$.

Wei-Lun Tsai, M. R.-F. (2018). Relationships between Characteristics of Urban Green Land Cover and Mental Health in U.S. Metropolitan Areas. International Journal of Environmental Research and Public Health, 1-12.

Wilma L. Zijlema, I. A.-P.-M. (2018). Active commuting through natural environments is associated with better mental health: Results from the PHENOTYPE project. Environment International 121, 721-727.

World Health Organization. (2014). Mental Health: A State of Well-being. Retrieved from World Health Organization: https://www.who.int/features/factfiles/mental_health/en/

World Health Organization. (2019, October 4). World health report. Retrieved from World Health Organization: https://www.who.int/whr/2001/media_centre/press_release/en/

Ye Liu, R. W. (2019). Exploring the linkage between greenness exposure and depression among Chinese people: Mediating roles of physical activity, stress and social cohesion and moderating role of urbanicity. Health and Place 58, 1-8.

Yi Gong, S. P. (2016). A systematic reviewof the relationship between objective measurements of the urban environment and psychological distress. Environment International 96, 48-57.

Yingqi Guo, C. H. (2019). Neighborhood environment and cognitive function in older adults: A multilevel analysis in Hong Kong. Health \& Place 58.

Yingzhi Qiu, Y. L. (2019). Exploring the Linkage between the Neighborhood Environment and Mental Health in Guangzhou, China. International Journal of Environmental Research and Public Health, 1-15. 